\title{
Identificando o Potencial de Inovação das organizações por meio da análise do portfólio de projetos de Tecnologia da Informação
}

\section{Identifying Innovation Potential in organizations through analysis of the Information Technology project portfolio}

\author{
José Ignácio Jaeger Neto' \\ Edimara Mezzomo Luciano' 1 \\ Mauricio Gregianin Testa ${ }^{1}$
}

\begin{abstract}
Resumo: A gestão do portfólio de projetos contribui para o desenvolvimento das estratégias e objetivos da organização e pode expressar o atual esforço de inovação em uma empresa. A pesquisa tem como tema o potencial de inovação do portfólio de projetos de Tecnologia da Informação. O objetivo é analisar o potencial de inovação do portfólio de projetos de TI, avaliando as características de inovação das ações empreendidas, considerando-se a abrangência da novidade das inovações para a própria empresa. A pesquisa utiliza uma abordagem exploratória por meio de estudo de casos múltiplos em três organizações de grande porte. Os dados analisados provêm dos projetos que fazem parte do portfólio de TI das organizações. A análise dos dados mostra que os critérios utilizados no artigo permitem identificar o potencial de inovação das organizações expresso por meio do portfólio de projetos, na medida em que as inovações são desenvolvidas por meio de projetos.
\end{abstract}

Palavras-chave: Projetos. Portfólio de projetos. Inovação. Tecnologia da Informação.

\begin{abstract}
Project portfolio management contributes to the development of organization strategies and objectives, and it can reveal the current innovation efforts in an organization. This research subject is the innovative potential of the Information Technology project portfolio. The objective is to analyze the innovation potential of the IT project portfolio through the evaluation of the characteristics of innovation activities considering the degree of novelty of these innovations. The present study uses an exploratory multiple case study approach in three large organizations. The data were obtained from the organizations' IT project portfolio. Data analysis shows that the criteria used can identify the organizations' innovation potential revealed through their project portfolio since innovations are promoted through these projects.
\end{abstract}

Keywords: Projects. Project portfolio. Innovation. Information technology.

\section{Introdução}

Inovação, de uma maneira genérica, remete à obtenção de resultados superiores em produtos e processos, introdução de novos modelos de negócios ou novas formas de gestão organizacional (TIDD; BESSANT; PAVITT, 2008), sendo necessária para a sustentabilidade e o crescimento das organizações (DAVILA; EPSTEIN; SHELTON, 2007). Ela é abrangente e complexa, envolve diferentes perspectivas, cuja compreensão depende de pontos de vista diferentes, conforme os interlocutores (ADAMS; BESSANT; PHELPS, 2006). Pode-se avaliar a inovação de modo macro, em que o foco é a indústria e o mercado, ou sob o ponto de vista micro, de uma empresa individualmente (GARCIA; CALANTONE, 2002). Segundo Zawislak (2008), as medidas correntes e tradicionais de inovação não explicam a totalidade desse fenômeno - principalmente, quando se aborda o comportamento inovador da empresa.

Atualmente a inovação figura como diferencial requerido à sustentabilidade em cenários altamente dinâmicos (PORTER; STERN, 2001). Para realizar melhorias contínuas e radicais, torna-se necessário gerenciar, ao longo do tempo, um grande número de projetos dos mais variados tipos, que tendem a utilizar

\footnotetext{
1 Programa de Pós-graduação em Administração - PPGAd, Pontifícia Universidade Católica do Rio Grande do Sul - PUCRS, Av. Ipiranga, 6681, Prédio 50, Sala 1105, CEP 90619-900, Porto Alegre, RS, e-mails: jaeger@ via-rs.net; eluciano@ pucrs.br; mauricio.testa@pucrs.br
} 
um conjunto de recursos escassos e compartilhados (KERZNER, 2002). O gerenciamento eficaz desses projetos torna-se, então, condição fundamental para os negócios e as atividades das empresas.

A utilização cada vez maior da TI para a manutenção e a geração de novos negócios tem gerado maior dependência da capacidade de realização de projetos pela área de TI. As estratégias procuram indicar formas de materialização dos objetivos empresariais, mas é por meio dos projetos e mais especificamente do portfólio de projetos que essa materialização acontece. Desta forma, quanto maior a dependência da TI para os negócios, maior a capacidade de que o portfólio de projetos de TI expresse o atual esforço de inovação em uma empresa. Logo, de posse de uma carteira de projetos organizada, a análise dos tipos de projetos em relação às características de inovação torna-se relevante, na medida em que a área de TI possa ressaltar os critérios que evidenciem a capacidade inovadora dos projetos na competitividade e crescimento da empresa, o que justifica o presente estudo.

Esta pesquisa se concentra no portfólio de projetos referente a produtos e serviços relacionados à área de TI em três estudos de caso, analisados com o intuito de identificar critérios que permitam descrever as características de inovação em projetos de TI, possibilitando analisar o potencial de inovação do portfólio de projetos das empresas selecionadas. Por potencial de inovação, entende-se a possibilidade ou a capacidade de o conjunto de projetos de TI contribuírem para que uma organização obtenha resultados relativos à inovação de produtos, processos, negócios ou gestão. Embora a inovação possa ser estudada sobre vários aspectos, esta pesquisa o faz pela análise do portfólio de projetos, uma vez que a transformação de uma ideia em inovação se torna viável a partir de projetos.

Na seção 2 deste artigo, descreve-se uma síntese do referencial teórico que embasou a pesquisa. $\mathrm{Na}$ seção 3, apresenta-se o método de pesquisa, enquanto que a seção 4 apresenta os resultados alcançados. A seção 5 apresenta as considerações finais.

\section{Referencial teórico}

O referencial teórico apresentado nesta seção aborda os principais conceitos sobre portfólio de projetos, inovação e a relação entre inovação e portfólio de TI.

\subsection{Portfólio de projetos}

O gerenciamento de projetos objetiva aumentar a eficiência dos projetos, por meio de requisitos tais como prazo, custo, qualidade e atendimento dos requisitos dos clientes (PROJECT..., 2008a), enquanto que a gestão de portfólio representa uma abordagem organizacional em que o objetivo é o atendimento das necessidades dos negócios (PROJECT..., 2008b).

Um portfólio é uma coleção de projetos ou programas que são agrupados para facilitar uma gestão eficaz e atender aos objetivos estratégicos das empresas (PROJECT..., 2008a). Para Terra, Rijnbach e Barroso (2009), a gestão de portfólio é o que liga as estratégias organizacionais com as iniciativas dos projetos, na qual as iniciativas estratégicas são o conjunto de ações de impacto direto no posicionamento competitivo da organização. O conceito de portfólio, abordado no seminal artigo Portfolio Selection (MARKOWITZ, 1952), deu origem à Teoria Moderna de Portfólio, ao considerar o desejo da diversificação dos investimentos. Na área de TI, o primeiro autor a explorar o tema de portfólio foi McFarlan (1981), que dirigiu seus estudos para os riscos relacionados ao gerenciamento de projetos de TI.

A gestão de portfólio oferece benefícios para a tomada de decisão baseada em informações estratégicas e prioridades. Essa prática pode também reduzir o desperdício causado pela alocação ineficiente de recursos ou a duplicação de esforços em projetos similares, bem como prover um processo racional para justificativa das decisões sobre projetos. Kendall e Rollins (2003) complementam que a ausência da gestão de portfólio pode levar as organizações a terem um número excessivo de projetos ativos, projetos em andamento que não agregam valor aos negócios, projetos que não estão alinhados aos objetivos estratégicos, assim como projetos prioritários sem os recursos adequados. Isso implica em um portfólio não balanceado, com muitos projetos de pequenas melhorias, em detrimento ao desenvolvimento de novos produtos, de pesquisa e de inovações. No entanto, a utilização de técnicas de gestão do portfólio de projetos ainda é recente nas organizações brasileiras (CASTRO; CARVALHO, 2010).

Os projetos competem por recursos escassos, o que requer a utilização de critérios efetivos na gestão de um portfólio. Assim, embora existam quase sempre inúmeros projetos potenciais, as empresas são levadas a adotar uma escala de prioridades na seleção dos projetos. Davila, Epstein e Shelton (2007) registram que, na gestão de um portfólio, procura-se avaliar o equilíbrio das várias iniciativas de inovação pela escolha dos projetos mais apropriados para os objetivos da empresa, utilizando técnicas, procedimentos e critérios que possam ser compreendidas facilmente pelos gestores responsáveis pela tomada de decisão.

\subsection{Inovação}

Tidd, Bessant e Pavitt (2008) definem inovação como o processo de transformar oportunidades em novas ideias e colocá-las em prática. Dodgson, Gann e Salter (2008) acrescentam que a inovação inclui as 
atividades científicas, tecnológicas, organizacionais, financeiras e comerciais necessárias à introdução de um novo (ou melhorado) produto ou serviço. Segundo o Manual de Oslo (ORGANIZAÇÃO..., 2005, p. 55), inovação é

[...] a implementação de um produto (bem ou serviço) novo ou significativamente melhorado, ou um processo, ou um novo método de marketing, ou um novo método organizacional nas práticas de negócios, na organização do local de trabalho ou nas relações externas.

Assim, inovação significa criar novas combinações (e não apenas uma pequena e gradual melhoria), aspecto abordado por Utterback e Abernathy, já em 1975, ao descreverem a inovação de produto como a combinação de tecnologias introduzidas comercialmente para atender a uma necessidade de mercado.

Várias são as terminologias empregadas na literatura acadêmica e profissional para conceituar tipologias de inovações. As inovações geralmente são caracterizadas sob a perspectiva do que é mudado e da extensão da mudança (SOUSA, 2006). Entre as diferentes abordagens do tema, estão o resultado ou tipo da inovação ou o grau de novidade envolvida, representando a dimensão da mudança, abordados a seguir.

Em relação ao tipo de inovação, as inovações podem ser classificadas como (ORGANIZAÇÃ̃..., 2005): a) inovação de produto: introdução de um bem ou serviço novo ou significativamente melhorado no que concerne a suas características ou a usos previstos; b) inovação de processo: implementação de um método de produção ou distribuição novo ou significativamente melhorado; c) inovação de marketing: implementação de um novo método de marketing com mudanças significativas na concepção do produto ou em sua embalagem, no posicionamento do produto, em sua promoção ou na fixação de preços; d) inovação organizacional: implementação de um novo método organizacional nas práticas de negócios da empresa, na organização do seu local de trabalho ou em suas relações externas.

Tidd, Bessant e Pavitt (2008) utilizam uma classificação similar para categorizar as inovações: a) inovação de produto: mudanças nos produtos/serviços que uma empresa oferece; b) inovação de processo: mudanças na forma em que os produtos/serviços são criados e entregues; c) inovação de posição: mudanças no contexto em que produtos/serviços são introduzidos; d) inovação de paradigma: mudanças nos modelos que orientam o que a empresa faz.

O conceito de tipo de inovação usado nesta pesquisa refere-se à forma pela qual uma inovação pode ser implementada, e que pode ser representada por uma novidade ou mudança significativa de produto, de processo, de negócio ou no nível organizacional. Essa perspectiva representa o que é mudado e caracteriza o resultado da inovação. Um aspecto importante relacionado à terminologia empregada para definir os tipos de inovações é que uma mesma inovação, dependendo do caso, poder ser classificada em mais de um desses tipos.

No que tange à dimensão da mudança, Garcia e Calantone (2002) citam que identificar as categorias de inovações apenas pela dicotomia radical e incremental é simplista. Uma terceira categoria é necessária, e o termo "realmente nova" é utilizado. Inovações radicais são inovações que provocam descontinuidades tecnológicas e de mercado, tanto em nível macro quanto micro. Inovações incrementais ocorrem somente em nível micro e causam uma descontinuidade de mercado ou tecnológica. Inovações realmente novas cobrem as combinações entre esses dois extremos. Davila, Epstein e Shelton (2007) utilizam as categorias de inovações incrementais, semirradicais e radicais já que as inovações não são criadas da mesma forma, apresentam-se diferentes e nem proporcionam recompensas diferentes. Tidd, Bessant e Pavitt (2008) empregam a mesma terminologia, que pode ir desde melhorias incrementais menores, passando pelas inovações semirradicais, até mudanças realmente radicais que transformam a forma como os produtos são vistos ou usados. Scherer, Bignetti e Carlomagno (2009) categorizam as inovações como incrementais, substanciais e radicais. Nagji e Tuff (2012), mais recentemente, desenvolveram a Matriz da Ambição da Inovação, utilizando as classificações de inovações como nuclear (core), adjacentes e transformacionais.

Fundamentadas nos preceitos de Graham e Englund (2004), estas descontinuidades apresentam algumas características concernentes à inovação dos projetos de TI, de acordo com a novidade da tecnologia e do mercado, a saber:

- Tecnologia nova em um novo mercado: o uso de uma nova tecnologia é sempre um desafio, e projetos desse tipo envolvem altas taxas de fracasso. Quando o mercado é novo, o problema se agrava devido à necessidade de maior participação do cliente e grupos de usuários, e a prototipação e um projeto piloto são elementos essenciais. Esses projetos representam risco muito alto, entretanto, seu sucesso pode trazer um alto retorno estratégico para a organização. Inovações desse tipo são classificadas como radicais;

- Tecnologia nova em um mercado conhecido: aplicações com uma nova tecnologia apresentam problemas específicos. Mesmo que o mercado seja conhecido, o produto não existe enquanto não for criado pelo projeto. Nesse caso, é 
necessário definir o produto e gerenciar as expectativas do cliente, tornando a necessidade de prototipação essencial. Parte desse trabalho é facilitada com o conhecimento do mercado e dos seus usuários. Projetos desse tipo envolvem risco alto e probabilidade de retorno alto. Inovações desse tipo são classificadas como semirradicais com descontinuidade na tecnologia;

- Tecnologia atual em um novo mercado: aplicações com tecnologia atual em um novo mercado exigem a capacidade de compreender os novos clientes. Nessa situação, muitos fornecedores falham ao conduzir um bom projeto - eles acreditam que, como dominam a tecnologia, o projeto tende a ser um sucesso, quando, na verdade, é preciso conhecer as novas aplicações para este novo cliente. Como existe um protótipo (a aplicação na tecnologia atual), a equipe deveria considerar como utilizá-lo em um novo mercado. Projetos desse tipo apresentam risco médio e probabilidade de retorno de médio a alto. Inovações desse tipo são classificadas como semirradicais com descontinuidade no mercado;

- Tecnologia atual em um mercado conhecido: quando o produto de um projeto envolve uma tecnologia atual em um mercado conhecido (uma nova aplicação para um cliente antigo), o fornecedor normalmente tem conhecimento sobre as potencialidades do produto, criando expectativas no cliente com a apresentação da aplicação usando a tecnologia atual. $\mathrm{O}$ conhecimento em detalhes das aplicações da tecnologia no produto beneficia a compreensão e a identificação das necessidades, apresentando baixo risco e normalmente envolvendo um retorno baixo. Inovações desse tipo são classificadas como incrementais.

Levando em conta a tipologia descrita para a dimensão da mudança em relação à descontinuidade do mercado e da tecnologia, as inovações de TI apresentam algumas características relacionadas a risco e retorno, conforme apresentado na Figura 1.

A aplicabilidade dessa classificação é aderente com a Matriz de Ansoff (ANSOFF; DECLERK; HAYES, 1990), em que os quadrantes representam estratégias de: 1) diversificação; 2) desenvolvimento de produto; 3) desenvolvimento de mercado; e 4) penetração de mercado. Tipologias relativas à dimensão da mudança são empregadas para diferenciar a descontinuidade de uma inovação de produto, processo, negócio ou organizacional em relação ao mercado e à tecnologia. $\mathrm{O}$ conceito de dimensão da mudança usado nesta pesquisa refere-se aos impactos causados pela implementação de uma inovação em relação à descontinuidade na tecnologia ou no mercado que pode ser categorizada como incremental, semirradical (mercado/tecnologia) ou radical. Essa perspectiva representa a extensão da mudança e caracteriza o grau de novidade envolvida. Definir a dimensão da mudança de uma inovação é essencial para a adequação das atividades de inovação em relação às estratégias e aos riscos, bem como em relação à vantagem competitiva.

Em relação à abrangência da novidade, a inovação pode ser analisada a partir de duas perspectivas: a) visão econômica, chamada de nível macro, em que as inovações estão relacionadas a um mercado ou indústria; b) visão da empresa, chamada de nível micro,

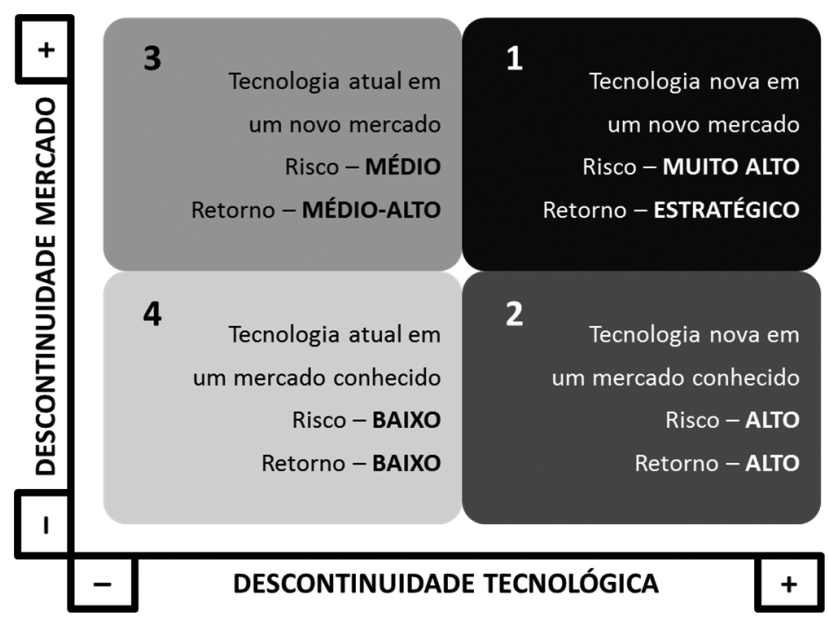

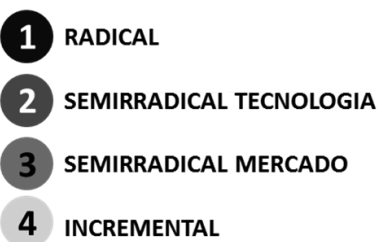

4 INCREMENTAL

Figura 1. Características relacionadas a risco e retorno das inovações de TI. Fonte: Elaborado pelos autores com base em Graham e Englund (2004). 
na qual o objeto é a análise individual da empresa e suas iniciativas relacionadas à inovação. Quando analisada por qualquer uma dessas perspectivas, tem consequências diretas no impacto da abrangência da novidade no mercado considerado e na dimensão da mudança tecnológica. No nível macro, a preocupação é avaliar a inovação quanto à sua novidade para o mercado ou indústria, e no nível micro quanto à sua novidade para a empresa ou cliente.

$\mathrm{O}$ requisito para se definir uma inovação é que ela seja nova (ou significativamente melhorada). Segundo o Manual de Oslo (ORGANIZAÇÃO..., 2005), isso inclui inovações desenvolvidas de forma pioneira na empresa, bem como aquelas que são adotadas de outras organizações. Pode ser algo já implementado por outras empresas e se ele é novo (ou significativamente melhorado) para a empresa, então, se trata de uma inovação para esta empresa. Logo, percebe-se que a novidade da inovação está na dependência 'de quem' a desenvolve e 'para quem' ela será oferecida. Esta pesquisa tem foco nas inovações sob o ponto de vista individual das empresas ou organizações, isto é, no nível micro da empresa.

\subsection{Relação entre inovação e portfólio de TI}

Adams, Bessant e Phelps (2006) consideram a gestão de portfólio e o gerenciamento de projetos como dimensões importantes do processo de avaliação da inovação na empresa, além da gestão do conhecimento, estratégia, organização, cultura e comercialização. A avaliação dos projetos em andamento numa organização é também apresentada por Zawislak (2008) como uma das formas de se medir a inovação nas empresas.

A importância dessas dimensões para a medição da inovação é justificada pelo fato de que, por mais complexas que sejam as dificuldades e os desafios de uma empresa para obter inovações, sem a existência de projetos as inovações provavelmente não irão acontecer. Para que uma empresa possa obter inovações - isto é, resultados de produtos, processos, negócios ou mudanças organizacionais - é necessário que ela se concentre no desenvolvimento e na implementação de projetos que permitam alcançar esses resultados. Em geral, a maioria das empresas trabalha com um portfólio de inovações, algumas das quais representam evoluções e melhorias incrementais em produtos já existentes, enquanto outras podem incidir diretamente em inovações radicais. Portanto, um portfólio é uma medida de intenção, de direção e de progresso da organização, bem como do potencial de inovação decorrente destas.

Para Zawislak (2008), medir o potencial de inovação dos projetos em um portfólio envolve analisar o perfil dos projetos realizados (tipos, gastos e a combinação de projetos). Deve-se estabelecer uma relação entre cada tipo de projeto e o tipo de inovação envolvida. Essa abordagem é complementar às avaliações preconizadas por Graham e Englund (2004), que estabelecem diferentes níveis de riscos e retorno de acordo com os tipos de inovações, assim como é aderente à proposta da Matriz da Ambição de Inovação desenvolvida por Nagji e Tuff (2012).

Entre os principais indicadores para avaliação dos projetos em um portfólio, encontram-se custo, retorno sobre o investimento, probabilidade de sucesso, tamanho do mercado, disponibilidade dos recursos humanos, ambiente tecnológico favorável, market-share, grau de compromisso organizacional e concorrência. Embora diferentes empresas tenham conjuntos distintos de portfólios, a maioria apresenta uma combinação de projetos de baixo risco e curto prazo com projetos de alto risco e longo prazo (CORMICAN; O'SULLIVAN, 2004). Os indicadores relacionados com as tipologias de inovação (tais como tipo de inovação e dimensão da mudança) fornecem elementos para a análise das distribuições dos projetos no portfólio, que estão mais diretamente relacionados com as estratégias e os negócios da empresa, bem como com os tipos de investimentos relativos ao potencial de inovações do portfólio. Por outro lado, os indicadores relacionados com os projetos do portfólio (tais como risco, tempo, valor, custos, recursos e competências) fornecem os elementos para comparações entre os investimentos representativos de cada projeto, demonstrando o nível de gastos e recursos que representam os projetos individualmente. Assim, pode-se analisar um portfólio de projetos de acordo com os tipos de inovações que esses projetos representam.

\section{Método de pesquisa}

A abordagem metodológica deste trabalho é de caráter exploratório, por meio de estudo de caso (YIN, 2005) de três organizações de grande porte do Estado do Rio Grande do Sul: Cia. de Processamento de Dados do Rio Grande do Sul (PROCERGS); Banco do Estado do Rio Grande do Sul (BANRISUL); e Hospital de Clínicas de Porto Alegre (HCPA). Optou-se pela utilização de estudo de casos múltiplos para possibilitar a análise de elementos diversificados de contexto organizacional e, dessa forma, obter maior amplitude de análise.

A coleta de dados utilizou múltiplas fontes de evidências, tais como entrevistas e coleta de dados de documentos de projetos, planilhas e sistemas informatizados das organizações. A primeira etapa da coleta de dados teve por objetivo reunir informações sobre a organização e sobre os projetos que compõem o portfólio de TI. Foram coletadas informações gerais sobre a organização, principais produtos e serviços, clientes e fontes de receitas e importância 
da inovação para os negócios. Também foram obtidas informações sobre o papel da TI nos negócios e a sua ligação com o plano estratégico. Essas informações foram utilizadas para identificar qual a importância da inovação em relação às estratégias organizacionais e à expectativa de contribuição da área de TI no alcance dos objetivos.

A segunda etapa consistiu da coleta de informações específicas sobre os projetos que compõem o portfólio da organização. Os projetos de interesse foram todos aqueles que estavam relacionados ao planejamento estratégico e que faziam uso de recursos de TI na entrega dos resultados. As informações foram utilizadas para identificar as características individuais de cada projeto, tais como prazo, custo e tamanho dos projetos. Inicialmente foram disponibilizados os seguintes dados sobre os projetos: nome, situação do projeto, data de início e de fim de cada projeto. Em relação ao tamanho do projeto, as organizações utilizam maneiras distintas e, em virtude disso, as seguintes variáveis foram consideradas: a) no caso da PROCERGS, considerou-se o valor do custo para a execução do projeto, sendo esse custo uma estimativa em ordem de grandeza utilizada como medida de comparação; b) no caso do BANRISUL, considerou-se a quantidade de horas para a realização do projeto, representando o esforço necessário para realizá-lo; c) para o HCPA, uma escala numérica do porte dos projetos foi utilizada, com os seguintes valores: 1 para projetos considerados pequenos (até dois meses); 2 para projetos médios (até seis meses); 4 para projetos considerados como grandes (até 12 meses).

A terceira etapa teve por objetivo coletar informações sobre os projetos em relação aos tipos de inovação e às dimensões das mudanças caracterizadas pelas descontinuidades no mercado e da tecnologia.

A fase de análise dos dados teve como objetivo avaliar o potencial de inovação do portfólio de projetos de TI. Como os projetos representam medidas de intenção para o alcance de objetivos estratégicos, as distribuições das inovações dos projetos no portfólio de cada organização foram analisadas considerando-se as particularidades de cada caso. Assim, para cada caso foram analisados temas relativos à empresa e ao negócio, planejamento estratégico, projetos de TI e inovação, que serviram de base para o entendimento do papel do portfólio de projetos e da inovação, relacionados à TI nos negócios e nas estratégias das organizações. Para cada caso, foi feita a classificação e totalização dos componentes do portfólio. Foram calculadas médias relacionadas ao tamanho (custo, horas ou pesos) e à duração dos projetos, assim como as quantidades de projetos de acordo com o tipo de inovação (produto, processo, negócio, organizacional). Também foram calculadas as distribuições percentuais das quantidades de projetos de acordo com as categorias de dimensão da mudança (radical, semirradical em tecnologias, semirradicial em mercado, incremental). Para todas estas análises, procurou-se apresentar uma interpretação dos resultados obtidos.

Analisando-se a distribuição das inovações, é possível identificar algumas das características do portfólio de projetos. Mapas de portfólio, como gráficos de bolha e grade ou matrizes de portfólio (KILLEN; HUNT; KLEINSCHMIDT, 2008), são um dos métodos de gestão de portfólio utilizados para auxílio no balanceamento do portfólio. Analisando-se a distribuição das inovações em mapas de portfólio, foi possível avaliar o potencial de inovação do portfólio de projetos, utilizando-se cores para a representação das categorias das inovações. A distribuição dos projetos mostra a carteira de inovações com as inovações incrementais, semirradicais em mercado, semirradiciais em tecnologia e radicais. Outra consideração importante refere-se ao volume de investimentos em cada inovação, representado pelo tamanho do elemento gráfico utilizado, neste caso, um gráfico de bolhas: quanto maior o tamanho da bolha, maior a quantidade de recursos investidos no projeto.

Finalmente, foi realizada a análise comparativa dos casos. Para isso, procurou-se identificar similaridades e diferenças das distribuições das tipologias de tipo de inovação e dimensão da mudança entre os portfólios de projetos dos casos estudados, considerando-se as quantidades, durações e tamanhos dos projetos. Os resultados obtidos foram ainda comparados com a teoria existente e com resultados de algumas pesquisas relacionadas.

\section{Resultados}

Esta seção apresenta os resultados da pesquisa. Os casos estudados são organizados em partes, contendo, para cada caso, uma descrição geral da organização, o resumo dos dados coletados e a análise do portfólio de projetos. Posteriormente, é feita a análise comparativa dos casos e revelam-se as observações mais relevantes que foram apuradas.

\subsection{Caso 1: PROCERGS}

A PROCERGS - Companhia de Processamento de Dados do Estado do Rio Grande do Sul é a maior empresa de informática do Estado. Fundada em 1972 e vinculada à Secretaria da Fazenda, é uma empresa de economia mista que presta serviços à Administração Pública, como secretarias e empresas controladas pelo Estado. Seu corpo funcional conta com cerca de 1.000 colaboradores, que asseguram um faturamento anual da ordem de 150 milhões de reais. As informações sobre o portfólio de projetos estratégicos da PROCERGS considerados compreendem o período do final de 2007 até o início de 2010, dividido em dois grupos, quais sejam, projetos de clientes e projetos internos. 
Projetos de clientes são os que a empresa desenvolve para o atendimento do seu negócio (prestação de serviços de TI para empresas do governo e órgãos da administração indireta, fundações e autarquias) e projetos internos são aqueles desenvolvidos para a sua própria operação.

No grupo de projetos de clientes, o portfólio soma 35 projetos, dos quais foram coletadas informações sobre tipos de inovações e dimensões da mudança. O resumo do portfólio estratégico de projetos de clientes é apresentado na Tabela 1.

A tabela mostra o portfólio dos 35 projetos estratégicos de clientes em relação a custo, duração, tipo de inovação e dimensão da mudança. A variação significativa entre os custos e as durações dos projetos representa uma alta diversidade de projetos, com tamanhos e complexidades diferentes. Essa ampla distribuição de custos e durações dos projetos, nem sempre diretamente relacionadas, mostra que as escolhas da empresa quanto à definição de prioridades está de acordo com as suas estratégias. No processo de priorização dos projetos de clientes, são considerados os aspectos relacionados com a relevância do cliente, a melhoria na prestação dos serviços ao cidadão e a própria repercussão financeira para a empresa. Com isso, o portfólio de projetos estratégicos de clientes possui tanto os maiores projetos (alto custo ou longa duração), como também projetos menores (baixo custo ou curta duração). Em razão de o portfólio analisado compreender projetos de clientes, nota-se maior concentração de projetos que dizem respeito à inovação de produtos e de processos, tipicamente relacionados ao desenvolvimento de novos sistemas ou implementação de aplicativos. Em relação à dimensão da mudança, percebe-se o uso de novas e atuais tecnologias, para novos e atuais mercados, consistente com o negócio da empresa que envolve múltiplos clientes com diferentes níveis de utilização da TI e com a estratégia da organização de atender tanto a novas quanto a atuais necessidades do seu mercado. A relação dos projetos de clientes é apresentada na
Figura 2, na qual as cores representam as categorias de dimensões da mudança e o tamanho da bolha representa o custo de cada projeto.

A análise dos projetos de clientes apresentados na Figura 2 possibilita evidenciar algumas percepções importantes em relação ao portfólio, conforme apresentado a seguir:

- Os projetos de inovação radical são, em geral, de curta duração e custo mais reduzido, com apenas um dos projetos com maior duração e um custo mais elevado. Este tipo de estratégia torna-se relevante em função dos riscos relacionados com o uso de novas tecnologias em novos mercados, mas com potencial de retorno para a empresa. Assim, manter uma parcela significativa de projetos de curta duração e custo reduzido torna-se uma opção adequada para esse tipo de investimento. Além disso, a existência de apenas um projeto de maior duração e custo mais elevado é também uma opção adequada de investimento em uma iniciativa de maior risco, mas que pode trazer maior retorno para a empresa;

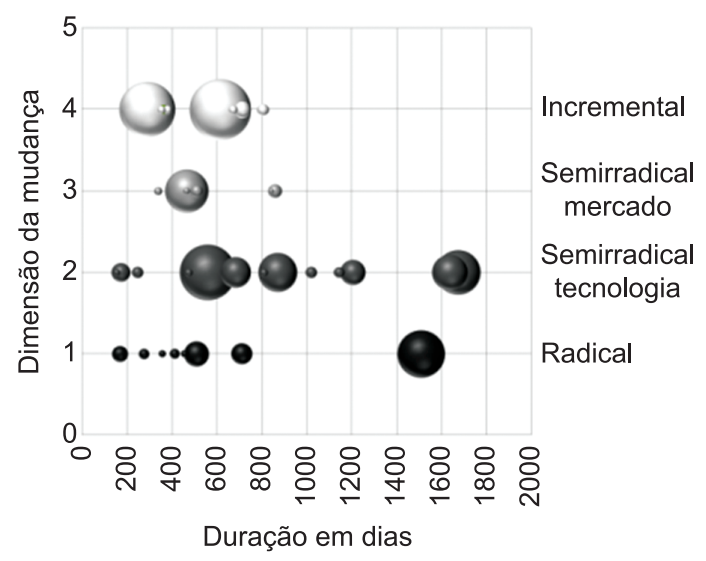

Figura 2. Projetos de clientes da PROCERGS por dimensão da mudança.

Tabela 1. Resumo do portfólio de projetos estratégicos de clientes da PROCERGS.

\begin{tabular}{|c|c|c|c|c|c|c|c|c|c|c|c|}
\hline \multicolumn{3}{|c|}{ Tamanho dos projetos } & \multicolumn{5}{|c|}{ Tipo de inovação } & \multicolumn{4}{|c|}{ Dimensão da mudança } \\
\hline & $\begin{array}{c}\text { Custo } \\
\text { (em R\$) }\end{array}$ & $\begin{array}{l}\text { Duração } \\
\text { (em dias) }\end{array}$ & & $\begin{array}{l}\stackrel{0}{E} \\
\stackrel{0}{0} \\
\text { D. }\end{array}$ & 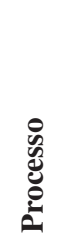 & 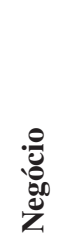 & 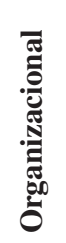 & 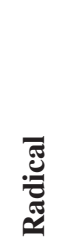 & 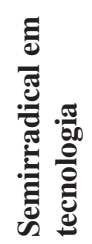 & 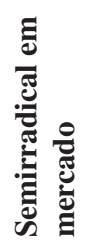 & 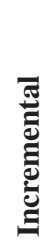 \\
\hline Soma & $38.374 .800,00$ & 22.647 & Soma $^{3}$ & 35 & 29 & 10 & 12 & 8 & 13 & 6 & 8 \\
\hline Média & $1.096 .422,861^{1}$ & $647^{2}$ & $\%$ & 100 & 83 & 29 & 34 & 23 & 37 & 17 & 23 \\
\hline
\end{tabular}

${ }^{1}$ Desvio padrão $1.633 .637,17 ;{ }^{2}$ Desvio padrão 400; ${ }^{3}$ Respostas múltiplas. 
- Para inovação semirradical em tecnologia, percebem-se variações mais significativas em relação à duração e ao custo, com projetos de curto, médio e longo prazo, assim como custos baixos, médios e altos. Investimentos desta natureza se caracterizam por novas tecnologias em um mercado conhecido, possibilidades de alto risco e retorno alto. Devido ao negócio da empresa (TI) e o seu mercado (governo), é esperado que uma grande parte dos investimentos estratégicos fosse feita em inovações de tecnologia para o seu mercado. A diversidade de clientes da empresa, com disponibilidade de recursos financeiros diferenciados para a contratação de serviços, é refletida nas variações de custo e duração dos projetos. Apesar dessa realidade, seria recomendável que a empresa tivesse maior parcela de investimentos nesta categoria, uma vez que este é o seu principal negócio;

- Projetos de inovação semirradical em mercado apresentam-se como projetos de baixo custo e menor duração, com apenas um projeto de curta duração e de custo mais elevado. Os investimentos nesta categoria que representam o uso de tecnologias atuais em novos mercados, em geral, apresentam risco médio e retorno de médio a alto. Como poucos são os projetos nesta categoria, a estratégia de investimentos torna-se também atraente;

- Por fim, projetos de inovação incremental são projetos de curta duração, mas que apresentam tanto custos mais baixos como elevados. Investimentos nesta área, que utilizam tecnologias atuais em mercados conhecidos, apresentam risco baixo e também um baixo retorno. Embora a duração dos projetos seja baixa, a existência de dois grandes investimentos nessa categoria deveria ser questionada, uma vez que o volume de recursos financeiros é alto e melhor aproveitamento poderia ser feito com o uso de novas tecnologias.

No grupo de projetos internos, o portfólio conta com 25 projetos, que representam iniciativas para implementar mudanças e ações na organização, normalmente relacionadas a melhorias no ambiente, infraestrutura, processos e gestão e a busca da inovação por meio de novas tecnologias, para que a empresa possa melhor atender a suas necessidades de negócio e manter a operação. O resumo do portfólio é apresentado na Tabela 2.

A tabela mostra o portfólio dos 25 projetos estratégicos internos. Há uma variação significativa entre os custos e as durações dos projetos, o que representa uma alta diversidade de projetos, com tamanhos e complexidades diferentes. A ampla distribuição de custos e durações nem sempre estão diretamente relacionadas, o que mostra que as escolhas da empresa quanto à definição de prioridades está de acordo com as suas estratégias. No processo de priorização dos projetos, são considerados aspectos relacionados aos investimentos em infraestrutura necessários para a prestação dos serviços e inovações para busca de novas tecnologias. Assim, o portfólio possui tanto os maiores projetos (alto custo ou longa duração), como também projetos menores (baixo custo ou curta duração).

Com relação ao tipo de inovações, já que portfólio compreende projetos internos, torna-se compreensível a maior concentração de projetos que dizem respeito à inovação de produtos e organizacionais, tipicamente relacionados a mudanças na infraestrutura e na forma de gestão da organização. Com relação à dimensão da mudança, o resultado pode ser justificado em razão das características dos projetos internos, orientados para novas tecnologias empregadas para impulsão de novos produtos, e de projetos de melhorias no ambiente e na infraestrutura requeridas para manter as operações. A Figura 3 mostra os projetos internos (no formato de bolhas). As cores representam as

Tabela 2. Resumo do portfólio de projetos estratégicos internos da PROCERGS.

\begin{tabular}{|c|c|c|c|c|c|c|c|c|c|c|c|}
\hline \multicolumn{3}{|c|}{ Tamanho dos projetos } & \multicolumn{5}{|c|}{ Tipo de inovação } & \multicolumn{4}{|c|}{ Dimensão da mudança } \\
\hline & $\begin{array}{c}\text { Custo } \\
(\text { em R\$) }\end{array}$ & $\begin{array}{l}\text { Duração } \\
\text { (em dias) }\end{array}$ & & 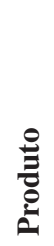 & 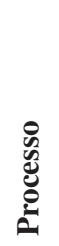 & 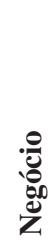 & 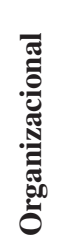 & 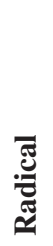 & 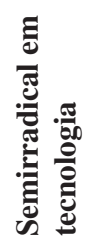 & 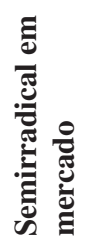 & 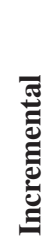 \\
\hline Soma & $41.918 .000,00$ & 17.634 & Soma $^{3}$ & 15 & 16 & 9 & 19 & 2 & 12 & 2 & 9 \\
\hline Média & $1.676 .720,00^{1}$ & $705^{2}$ & $\%$ & 60 & 64 & 36 & 76 & 8 & 48 & 8 & 36 \\
\hline
\end{tabular}

${ }^{1}$ Desvio padrão $3.079 .508,40 ;{ }^{2}$ Desvio padrão $457 ;{ }^{3}$ Respostas múltiplas. 
categorias de dimensões da mudança e o tamanho da bolha representa o custo de cada projeto.

A análise dos projetos internos apresentados na Figura 3 possibilita evidenciar algumas percepções importantes em relação ao portfólio, conforme apresentado a seguir:

- Apenas dois projetos de inovação radical constam no portfólio, um de média e outro de longa duração, mas ambos de custos baixos. A pequena quantidade de projetos nesta categoria é justificada pela natureza dos projetos internos que, em geral, estão relacionados a investimentos internos da empresa e não diretamente para clientes e mercado. Devido ao fato de as duas iniciativas envolverem implementações de novos processos ou mudanças na organização, elas foram classificadas nessa categoria. Investimentos deste tipo poderiam compreender maior quantidade de projetos ou maiores recursos financeiros, embora a quantidade atual possa ser caracterizada como adequada. Os maiores problemas com estes projetos estão relacionados aos altos riscos e, nem sempre, o retorno estratégico é garantido. Entretanto, inovações na área de processos ou organizacionais podem representar alternativas de diversificações além da inovação de produtos;

- Os projetos de inovação semirradical em tecnologia mostram uma prevalência de altos custos, com uma ampla variação em relação à duração. Aqui se encontram os grandes investimentos e a maior quantidade de iniciativas da empresa, na qual estão representadas as estratégias de novas tecnologias e inovações para fornecer produtos e serviços aos seus clientes e usuários. A diversidade de opções nesta área pode ser justificada pela necessidade

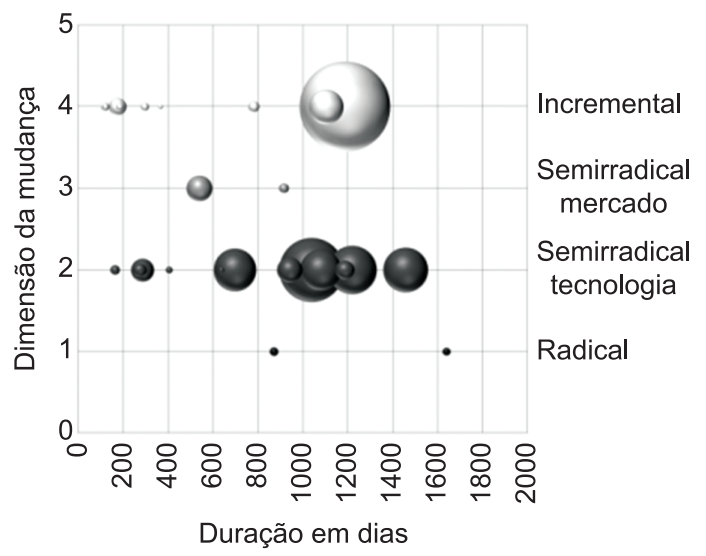

Figura 3. Projetos internos da PROCERGS por dimensão da mudança. de investimentos nesta categoria, que, embora represente altos custos, possui alto potencial de retorno. Investimentos desse tipo têm por objetivo a busca de vantagens competitivas;

- Projetos de inovação semirradical em mercado representam custos menores e média duração. Apenas dois projetos foram incluídos nesta categoria e representam situações especiais sobre as quais a empresa quer manter um controle no nível estratégico;

- Nos projetos de inovações incrementais, prevalece uma duração menor e baixos custos, com exceção de um projeto (média duração e alto custo). Nesta categoria, estão os investimentos relacionados à necessidade da empresa manter o nível de serviços e a capacidade de atendimento dos clientes e usuários e, por isso, muitas vezes são necessários altos volumes financeiros. $\mathrm{O}$ recomendável nesta área seriam investimentos contínuos ao longo do tempo, para minimizar a necessidade de altos recursos em determinados períodos.

\subsection{Caso 2: BANRISUL}

O BANRISUL - Banco do Estado do Rio Grande do Sul é o $8^{\circ}$ maior banco do Brasil. Fundado em 1928, é uma sociedade de economia mista constituída sob a forma de sociedade anônima. Possui 9.035 colaboradores, está presente em $82 \%$ dos municípios com 429 agências, 279 postos de atendimento, 452 pontos de Banrisul-Eletrônico e uma carteira de 2,8 milhões de clientes. O perfil dos clientes do banco são pessoas físicas, micro, pequenas, médias e grandes empresas. Como banco múltiplo, o grupo de empresas do BANRISUL oferece uma ampla variedade de produtos e serviços financeiros, incluindo cartões de crédito, seguros, previdência privada, grupos de consórcios e administração de recursos de terceiros.

As informações sobre o portfólio de projetos estratégicos de TI do BANRISUL considerados nesta pesquisa compreendem o período do final de 2008 até o início de 2010, totalizando 34 projetos. Além de um planejamento estratégico corporativo para todo o banco, existe também um portfólio de projetos estratégicos da área de TI, que representa, entre todas as iniciativas da área, um conjunto específico de projetos que são definidos como estratégicos por estarem diretamente relacionados às metas, objetivos e estratégias da organização. O resumo do portfólio estratégico de projetos de TI é apresentado na Tabela 3.

A tabela mostra o portfólio dos 34 projetos estratégicos de TI. Pode-se observar uma variação significativa entre a quantidade de horas e as durações dos projetos, o que representa uma alta diversidade de 
projetos, com tamanhos e complexidades diferentes. No processo de priorização, as iniciativas da área de TI seguem as diretrizes do planejamento estratégico do banco, de tal forma que as demandas para a área de TI já chegam priorizadas. Além disso, a complexidade dos projetos na área de TI é decorrência das ligações entre os demais projetos, que podem envolver múltiplas plataformas e sistemas legados. Com isso, o portfólio de projetos estratégicos de TI é constituído por iniciativas totalmente alinhadas com as estratégias do banco, o que também se justifica pela alta dependência da TI para os negócios.

Com relação ao tipo de inovações, em razão de o portfólio compreender projetos que representam iniciativas estratégicas na busca de novos serviços para novos clientes e mercados, nota-se maior concentração de projetos que dizem respeito à inovação de negócios, tipicamente relacionados a sistemas e aplicações que são a base para a operação.

Com relação à dimensão da mudança, não há projetos para inovações semirradicais de tecnologia. Esse resultado demonstra uma forte atuação em termos de utilização de novas tecnologias e soluções para novos mercados, coerente com as estratégias da organização quanto ao uso da TI para alavancar novos negócios. A relação dos projetos de TI pode ser observada na Figura 4, apresentada no formato de bolhas, nas quais as cores representam as categorias de dimensões da mudança e o tamanho da bolha representa o custo de cada projeto.

A análise dos projetos estratégicos da área TI apresentados na Figura 4 possibilita evidenciar algumas percepções importantes em relação ao portfólio:

- Os projetos de inovação radical são, em geral, os que demandam maior quantidade de horas e que possuem maiores durações para a sua realização, representando os grandes desafios em relação ao uso de novas tecnologias para novos negócios. Este tipo de estratégia apresenta grande potencial de retorno estratégico, embora estejam associados a riscos muito altos. Nota-se com isso, a alta importância das iniciativas da área de TI para os negócios da empresa, em especial devido à competitividade existente na área de serviços bancários;

- Não foram encontrados projetos de inovação semirradical em tecnologia no portfólio de projetos estratégicos. Isso pode ser justificado pelo fato das prioridades para os projetos da área de TI seguirem as estratégias do banco, definidas pelas diretrizes do planejamento estratégico, fazendo com que a área de TI receba as suas demandas com as prioridades já definidas. Assim, investimentos em inovações semirradicais em tecnologias podem existir, mas não ficam caracterizados como parte do planejamento estratégico;

- Por outro lado, projetos de inovação semirradical em mercado, embora possuam uma grande diversificação em relação à duração, utilizam em geral uma menor quantidade de horas, uma vez que as questões tecnológicas nesses projetos já são conhecidas pela organização. A existência de investimentos deste tipo está relacionada com sistemas e aplicações legadas, que usam tecnologia atual, mas que fazem parte

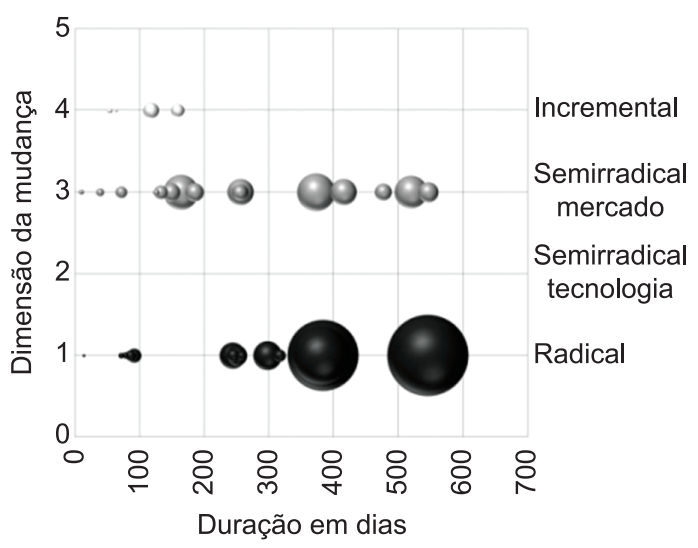

Figura 4. Projetos de TI do BANRISUL por dimensão da mudança.

Tabela 3. Resumo do portfólio de projetos estratégicos de TI do BANRISUL.

\begin{tabular}{|c|c|c|c|c|c|c|c|c|c|c|c|}
\hline \multicolumn{3}{|c|}{ Tamanho dos projetos } & \multicolumn{5}{|c|}{ Tipo de inovação } & \multicolumn{4}{|c|}{ Dimensão da mudança } \\
\hline & Horas & $\begin{array}{l}\text { Duração } \\
\text { (em dias) }\end{array}$ & & 葛 & 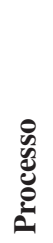 & 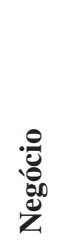 & 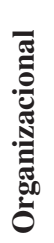 & 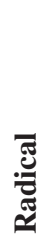 & 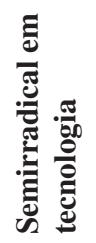 & 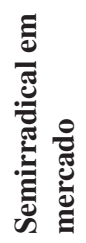 & 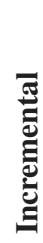 \\
\hline Soma & 89.816 & 7.604 & Soma $^{3}$ & 5 & 2 & 26 & 1 & 14 & 0 & 16 & 4 \\
\hline Média & $2.642^{1}$ & $224^{2}$ & $\%$ & 15 & 6 & 76 & 3 & 41 & 0 & 47 & 12 \\
\hline
\end{tabular}

${ }^{1}$ Desvio padrão 5.126; ${ }^{2}$ Desvio padrão $157 ;{ }^{3}$ Respostas múltiplas. 
dos recursos necessários aos serviços e produtos usados para atuações em novos mercados e clientes. Assim, encontram-se várias iniciativas nesta categoria, o que representa uma estratégia adequada para a manutenção de vantagens competitivas e crescimento dos negócios;

- Por fim, os projetos de inovação incremental apresentam uma pequena quantidade de horas necessária para a sua realização e curtas durações. Os investimentos nesta categoria representam o uso de tecnologias atuais em mercados conhecidos, com risco baixo e baixo retorno. A existência de alguns poucos projetos nessa categoria justifica-se pela alta integração e dependência entre sistemas e aplicações novas e legadas, fazendo com que projetos desse tipo sejam necessários à viabilidade de implementação de outros projetos.

\subsection{Caso 3: HCPA}

O HCPA - Hospital de Clínicas de Porto Alegre, criado em 1970, é uma empresa pública de direito privado, integrante da rede de hospitais universitários do Ministério da Educação e vinculado academicamente à Universidade Federal do Rio Grande do Sul (UFRGS). O hospital conta com 4.793 funcionários e uma ampla e qualificada infraestrutura. O negócio do hospital é definido como assistência, ensino e pesquisa em saúde.

As informações sobre o portfólio de projetos estratégicos de TI do HCPA considerados nesta pesquisa compreendem o período do início de 2008 até a metade de 2010, totalizando 23 projetos. O HCPA tem planejamento estratégico corporativo e um portfólio de projetos da área TI, que representa todas as iniciativas da área, que estão diretamente relacionados às metas, objetivos e estratégias da organização (Tabela 4).

A tabela mostra o portfólio dos 23 projetos estratégicos de TI. Pode-se observar uma pequena variação entre a duração dos projetos, demonstrando uma carteira equilibrada de projetos em relação às suas durações. A distribuição é resultado das métricas utilizadas na área de TI que determinam a capacidade de realização concorrente de projetos de pequeno, médio e grande porte, e, também, pelo fato de o portfólio analisado conter todas as iniciativas de projetos da TI e não apenas um subconjunto menor de alguns projetos estratégicos. Todos os projetos da área de TI estão relacionados com as estratégias e alguns deles podem estar diretamente ligados a determinados objetivos. Com relação ao tipo de inovação, pode-se observar uma distribuição equilibrada de projetos de inovações de produtos, processos e organizacionais, o que mostra o papel da TI no apoio aos processos e serviços da organização.

Com relação à dimensão da mudança, o resultado equilibrado pode ser explicado pelo fato de que nesta foi analisada a totalidade dos projetos da área TI e não apenas um grupo específico de projetos estratégicos. A relação dos projetos de TI, apresentada no formato de bolhas, em que as cores representam as categorias de dimensões da mudança, e o tamanho da bolha representa o custo de cada projeto, pode ser observada na Figura 5.

A análise dos projetos da área TI apresentados na Figura 5 possibilita evidenciar algumas percepções importantes em relação ao portfólio, conforme apresentado a seguir:

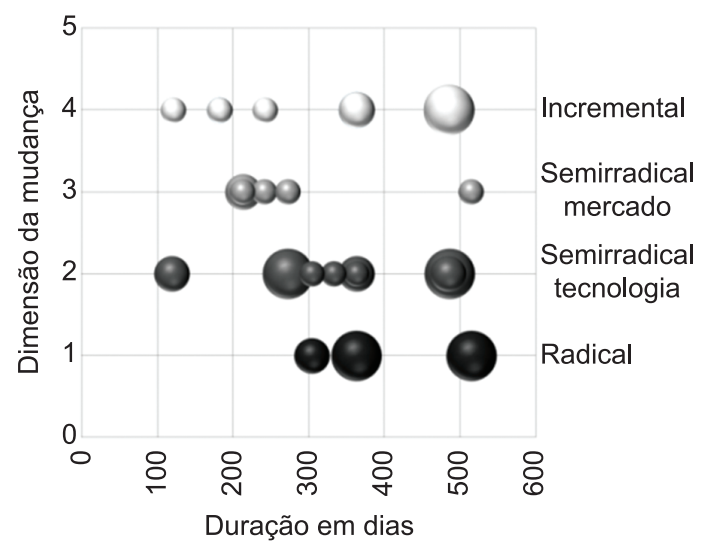

Figura 5. Projetos de TI do HCPA por dimensão da mudança.

Tabela 4. Resumo do portfólio de projetos estratégicos de TI do HCPA.

\begin{tabular}{|c|c|c|c|c|c|c|c|c|c|c|c|}
\hline \multicolumn{3}{|c|}{ Tamanho dos projetos } & \multicolumn{5}{|c|}{ Tipo de inovação } & \multicolumn{4}{|c|}{ Dimensão da mudança } \\
\hline & Peso & $\begin{array}{r}\text { Duração } \\
\text { (em dias) }\end{array}$ & & 总 & 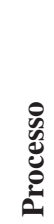 & 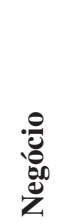 & 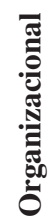 & 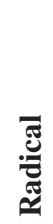 & 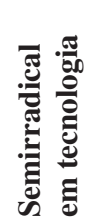 & 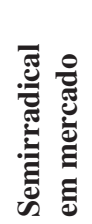 & 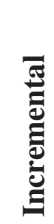 \\
\hline Soma & 45,0 & 7.296 & Soma $^{3}$ & 10 & 12 & 2 & 0 & 3 & 8 & 5 & 7 \\
\hline Média & $1,96^{1}$ & $317^{2}$ & $\%$ & 43 & 52 & 9 & 0 & 13 & 35 & 22 & 30 \\
\hline
\end{tabular}

${ }^{1}$ Desvio padrão 1,$19 ;{ }^{2}$ Desvio padrão $122 ;{ }^{3}$ Respostas múltiplas. 
- Os projetos de inovação radical são, em geral, projetos grandes (peso maior), com maior duração, com grandes desafios em relação ao uso de novas tecnologias para novos negócios, grande potencial de retorno estratégico e associados a riscos muito altos. Nota-se que uma menor quantidade de projetos e recursos é aplicada nestas iniciativas, o que demonstra a existência de investimentos, mas também controle em relação aos gastos. Esta distribuição pode ser avaliada como adequada ao tipo de negócio e condições de mercado;

- Projetos de inovação semirradical em tecnologia são projetos pequenos e médios (pesos menor e médio) que possuem durações diversificadas, por dependerem da complexidade da tecnologia utilizada. Aqui se encontram os maiores investimentos e a maior quantidade de iniciativas da área de TI, representadas pelo uso de novas tecnologias para suporte às atividades dos serviços e usuários. A dependência do uso da TI para as atividades e serviços do hospital, justifica a necessidade de projetos nesta categoria, por meio das quais as inovações de produtos e processos são disponibilizadas;

- Projetos de inovação semirradical em mercado, em geral, são projetos pequenos (peso menor) e com menor duração. Os investimentos nesta categoria representam novos usuários de sistemas e aplicações baseadas em tecnologia atuais. São necessários para ampliar o uso da TI nos processos e serviços do hospital;

- Por fim, os projetos de inovação incremental apresentam uma tendência a serem projetos pequenos e de curta duração, com exceção de dois projetos, um médio e outro grande. Investimentos nesta área usam tecnologias atuais em mercados conhecidos, com risco baixo e retorno baixo. A diversidade de iniciativas nesta área justifica-se pelo fato do portfólio de projetos de TI incluir todas as iniciativas da área, e não apenas alguns projetos classificados como estratégicos. Assim, demandas deste tipo são naturalmente encontradas em portfólios de projetos de TI que possuem aplicações e sistemas que continuam a ser desenvolvidos com as tecnologias atuais para os atuais usuários.

\section{Considerações finais}

Esta pesquisa analisou o portfólio de projetos estratégicos de TI em três empresas. A Tabela 5 (a seguir) mostra um resumo dos dados coletados.
A análise da distribuição dos tipos de inovações por empresa possibilita evidenciar algumas percepções importantes em relação ao portfólio de projetos:

- Na PROCERGS, o portfólio de projetos de clientes (35) possui maior concentração em inovações de produtos (100\%) e de processos (83\%), pois representam implementações de sistemas e aplicações, parte principal do seu negócio voltado ao atendimento das demandas dos clientes. O portfólio de projetos internos (25) apresenta maior concentração em inovações organizacionais (76\%), seguido de inovações de processos $(64 \%)$ e de produtos $(60 \%)$, pois se referem à infraestrutura, processos e mudanças organizacionais necessários para a gestão, operação e manutenção dos serviços e negócios;

- No BANRISUL, o portfólio de 34 projetos estratégicos de TI apresentou maior concentração em inovações de negócios (76\%), representando a principal estratégia na priorização dos projetos da área de TI, voltadas para o mercado e clientes, por meio da viabilização de novos negócios para o banco;

- Por fim, no caso do HCPA, o portfólio de 23 projetos de TI, considerando-se a totalidade das iniciativas da área, obteve maior concentração em inovações de processos (52\%) e produtos (43\%). Nesse caso, pode-se observar a TI atuando como função de suporte às atividades do hospital, por meio de novos sistemas ou novos processos.

Nas três empresas pesquisadas, observam-se distribuições diferenciadas em relação aos tipos de inovações dos projetos, que parecem estar de acordo com o tipo de atividade das organizações, demonstrando o alinhamento com as estratégias das empresas. Desta forma, a análise do portfólio de projetos de acordo com o tipo de inovação se apresenta como medida útil para validação das iniciativas de projetos quanto ao seu potencial de gerar inovação de produtos, processos, negócios e organizacionais. Além disso, o uso de indicadores dessa natureza mostra-se como uma alternativa complementar para demonstração de valor da TI e do papel de integração que ela representa nos negócios das empresas.

Procurou-se também definir uma tipologia para classificação das inovações que possibilitasse uma diferenciação entre o nível de novidade da tecnologia e do mercado, resultando em quatro categorias de dimensões das mudanças: radicais, semirradicais em tecnologia, semirradicais em mercado e incrementais. A Tabela 6 apresenta a distribuição da quantidade de projetos das categorias de dimensões das mudanças de inovações nas empresas. 
Tabela 5. Distribuição dos tipos de inovações nas empresas.

\begin{tabular}{|c|c|c|c|c|c|c|c|c|}
\hline \multirow{3}{*}{ Tipo de inovação } & \multicolumn{4}{|c|}{ PROCERGS } & \multirow{2}{*}{\multicolumn{2}{|c|}{ BANRISUL }} & \multirow{2}{*}{\multicolumn{2}{|c|}{ HCPA }} \\
\hline & \multicolumn{2}{|c|}{ Clientes } & \multicolumn{2}{|c|}{ Internos } & & & & \\
\hline & Qtd & Percentual & Qtd & Percentual & Qtd & Percentual & Qtd & Percentual \\
\hline Produto & 35 & $100 \%$ & 15 & $60 \%$ & 5 & $15 \%$ & 10 & $43 \%$ \\
\hline Processo & 29 & $83 \%$ & 16 & $64 \%$ & 2 & $6 \%$ & 12 & $52 \%$ \\
\hline Negócio & 10 & $29 \%$ & 9 & $36 \%$ & 26 & $76 \%$ & 2 & $9 \%$ \\
\hline Organizacional & 12 & $34 \%$ & 19 & $76 \%$ & 1 & $3 \%$ & 0 & $0 \%$ \\
\hline Número de projetos * & 35 & - & 25 & - & 34 & - & 23 & - \\
\hline
\end{tabular}

* As indicações de projetos em cada categoria de tipo de inovação admitem classificações em mais de uma categoria. Dessa forma, os valores de Número de projetos representam as quantidades totais de projetos e não o somatório das quantidades em cada categoria.

Tabela 6. Distribuição de projetos por dimensões das mudanças nas empresas.

\begin{tabular}{|c|c|c|c|c|c|c|c|c|}
\hline \multirow{3}{*}{$\begin{array}{c}\text { Dimensão da } \\
\text { mudança }\end{array}$} & \multicolumn{4}{|c|}{ PROCERGS } & \multirow{2}{*}{\multicolumn{2}{|c|}{ BANRISUL }} & \multirow{2}{*}{\multicolumn{2}{|c|}{ HCPA }} \\
\hline & \multicolumn{2}{|c|}{ Clientes } & \multicolumn{2}{|c|}{ Internos } & & & & \\
\hline & Qtd & Percentual & Qtd & Percentual & Qtd & Percentual & Qtd & Percentual \\
\hline Radical & 8 & $23 \%$ & 2 & $8 \%$ & 14 & $41 \%$ & 3 & $13 \%$ \\
\hline Semirradical tecnologia & 13 & $37 \%$ & 12 & $48 \%$ & 0 & $0 \%$ & 8 & $35 \%$ \\
\hline Semirradical mercado & 6 & $17 \%$ & 2 & $8 \%$ & 16 & $47 \%$ & 5 & $22 \%$ \\
\hline Incremental & 8 & $23 \%$ & 9 & $36 \%$ & 4 & $12 \%$ & 7 & $30 \%$ \\
\hline Número de projetos & 35 & $100 \%$ & 25 & $100 \%$ & 34 & $100 \%$ & 23 & $100 \%$ \\
\hline
\end{tabular}

A análise da distribuição da quantidade de projetos das categorias de dimensões das mudanças por empresa possibilita evidenciar algumas percepções importantes em relação ao portfólio de projetos. Pode-se observar que, para a PROCERGS, em relação à quantidade de projetos, inovações semirradicais em tecnologia tiveram predominância em projetos de clientes $(37 \%)$ e em projetos internos (48\%). Da mesma forma, para o HCPA, as inovações semirradicais em tecnologia tiveram predominância em relação à quantidade de projetos (35\%). Por outro lado, no caso do BANRISUL, inovações semirradicais em mercado (47\%) e inovações radicais $(41 \%)$ apresentam predominância em relação à quantidade de projetos.

Nas três empresas pesquisadas, essas distribuições podem ser consideradas como resultados de diferentes estratégias de atendimento das necessidades de negócio e mercado entre as empresas. Enquanto PROCERGS e HCPA utilizam projetos de TI como instrumentos para alavancagem dos seus produtos e processos por meio de novas tecnologias para o mercado atual, o BANRISUL possui uma estratégia forte de uso da TI com tecnologias novas ou atuais para alavancar negócios em novos mercados. Assim, a análise do portfólio de projetos, de acordo com a dimensão da mudança, apresenta-se como medida útil para validação das iniciativas de projetos quanto ao seu potencial de gerar inovações radicais, semirradicais em tecnologia, semirradicais em mercado e incrementais. Além disso, o uso de indicadores dessa natureza mostra-se como uma alternativa complementar para demonstração de valor da TI e do papel de integração que ela representa nos negócios das empresas.

Algumas pesquisas apresentam resultados relacionados ao percentual de distribuição das inovações com uma escala de três níveis. Os estudos de Garcia e Calantone (2002) indicaram uma distribuição das inovações em $12,5 \%$ para inovações radicais, $50 \%$ para inovações realmente novas e $37,5 \%$ para inovações incrementais. Esses valores estariam alinhados aos estabelecidos por Maidique e Ziger (1984), que separaram as categorias de inovações em 16,7\% para avanços radicais, 58,3\% para mudanças técnicas significativas e $25 \%$ para mudanças incrementais. Kleinschmidt e Cooper (1991) chegaram a resultados de $30 \%$ para inovação alta, $47 \%$ para inovação moderada e $23 \%$ para inovação baixa. Em uma análise sobre os tipos de produtos comercializados pelas empresas por um período de cinco anos, Griffin (1997) observou que 28,2\% das inovações correspondiam a novos produtos lançados no mercado, enquanto que $23,1 \%$ se tratava de adições de novos produtos a uma linha já existente e 48,7\% representavam apenas mudanças e melhorias nos produtos atuais.

Estudos mais recentes de Nagji e Tuff (2012) sugerem que, em média, empresas de alto desempenho canalizam $10 \%$ dos recursos destinados a iniciativas transformadoras, $20 \%$ a oportunidades adjacentes e $70 \%$ à inovação para aprimorar aquilo que já oferecem. Mas, por boas razões estratégicas, uma empresa pode 
favorecer outra proporção. Entre as distribuições observadas e que faziam sentido para empresas em circunstâncias diversas, as seguintes distribuições para inovações transformadoras-adjacentes-nucleares foram encontradas: (1) uma grande fabricante de bens de consumo: 2-80-80; (2) um grupo industrial diversificado: 10-20-70; (3) uma empresa de tecnologia em estágio intermediário: 15-40-45. Para buscar uma forma de comparação dos resultados da distribuição das categorias de dimensões das mudanças de inovação, foi feita a totalização das inovações desta pesquisa, mantendo-se as categorias de inovações radicais e incrementais, mas agrupando-se as inovações semirradicais em tecnologia e semirradicais em mercado em apenas uma única categoria de inovações semirradicais. Assim, os resultados demonstram a distribuição dos casos da PROCERGS em projetos de clientes com inovações radicais (23\%), semirradicais $(54 \%)$ e incrementais (23\%) e projetos internos com inovações radicais (8\%), semirradicais $(56 \%)$ e incrementais (36\%). No caso do BANRISUL, os resultados apresentam inovações radicais (41\%), semirradicais $(47 \%)$ e incrementais $(12 \%)$. Por fim, no caso do HCPA, os resultados apresentam inovações radicais (13\%), semirradicais $(57 \%)$ e incrementais (30\%). Conforme apresentado na Figura 6, agrupando-se as inovações semirradicais, observa-se, em todos os casos analisados, maior predominância de inovações desse tipo. Esses resultados estão consistentes com as pesquisas realizadas pelos autores citados anteriormente.

De acordo com Kumar, Ajjan e Niu (2008), empresas de alto desempenho, em termos de percentual de receitas de novos produtos, possuem maior proporção de projetos de inovação no seu portfólio do que as empresas de menor desempenho, o que demonstra a importância das características de inovação dos projetos em um portfólio. Pode-se observar a existência de um equilíbrio adequado das categorias de dimensões das mudanças de inovações no portfólio de projetos dos casos analisados nesta pesquisa. Estes resultados são compatíveis com os percentuais de empresas de tecnologia observados por Nagji e Tuff (2012).

A análise mostrou que as empresas estudadas possuem uma carteira de projetos com um potencial de gerar inovações de acordo com as perspectivas do que é mudado (produto, processo, negócio, organizacional) e da extensão percebida pela mudança (incrementais, semirradicais em mercado, semirradicais em tecnologia, radicais). A avaliação das iniciativas no portfólio mostra uma composição equilibrada de projetos, cujas distribuições são também consistentes com outras pesquisas. A análise do potencial de inovação não fornece uma receita do nível de distribuição das inovações no portfólio de projetos, mas permite que os gestores possam comparar os atuais investimentos na carteira de projetos e adequar sua distribuição de acordo com as estratégias da organização. De acordo com Nagji e Tuff (2012), para uma empresa de bens de consumo o sucesso como grande inovadora pode significar investir em iniciativas para pequenas extensões em linhas de produtos existentes, enquanto uma empresa de alta tecnologia pode assumir riscos maiores em inovações mais ousadas em troca da possibilidade de retorno maior.

Assim, pode-se concluir que as empresas analisadas possuem uma distribuição de investimento no portfólio de projetos de TI com potencial de inovação adequado a sua área de atuação, coerente com as estratégias e alinhados aos negócios. Portanto, o portfólio de projetos de TI demonstra que as empresas continuam a empreender atividades de projetos que possibilitam se manter à frente com vantagens competitivas. Isso expressa uma dimensão importante da inovação, analisada por meio do portfólio de projetos. A busca do equilíbrio adequado destes investimentos é uma decisão de cada organização, mas, embora pareça óbvio, poucas empresas pensam sobre o melhor nível de inovação a buscar (NAGJI; TUFF, 2012).

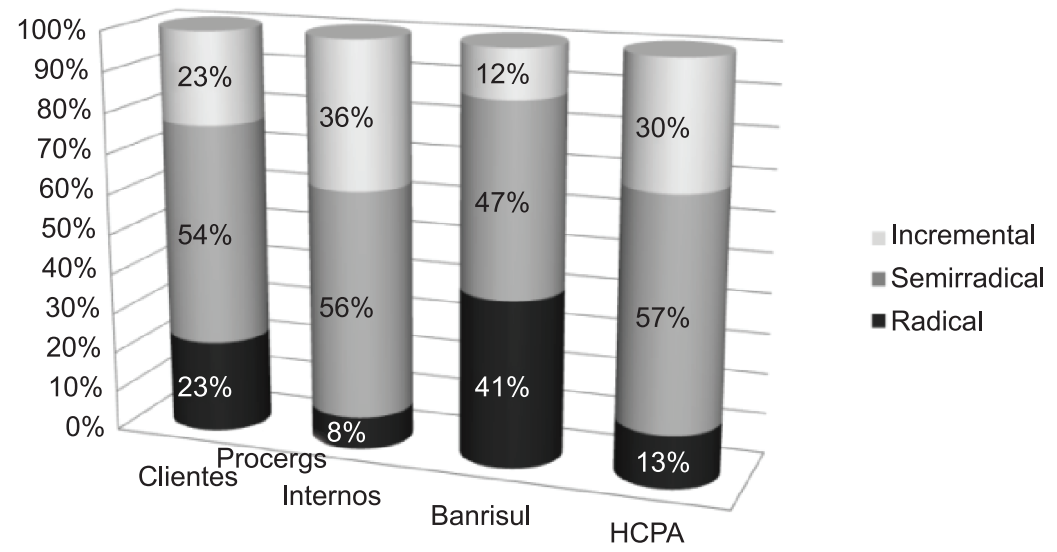

Figura 6. Percentual das categorias de dimensões das mudanças agrupadas por empresa. 
Pela análise do portfólio de projetos de TI e o seu potencial de inovação para as organizações dos três casos estudados, foi possível realizar uma avaliação detalhada da distribuição e do equilíbrio dos projetos no portfólio. Foram feitas considerações sobre os projetos quanto ao potencial de gerar inovações de acordo com o tipo de inovação (produto, processo, negócio ou organizacional) e da dimensão da mudança (incrementais, semirradicais em mercado, semirradicais em tecnologia ou radicais). Igualmente, foram encontradas evidências de alinhamento entre as distribuições dos projetos, segundo as tipologias de inovações utilizadas e as estratégias das organizações. Em algumas situações específicas, foram feitas recomendações sobre possíveis ajustes que poderiam contribuir para melhor distribuição dos projetos no portfólio. $\mathrm{O}$ estudo de novas possibilidades de avaliação do portfólio de projetos de TI, em especial em relação ao potencial de inovação aqui, atende à necessidade cada vez maior de integração da área de TI com as estratégias de negócios.

Apesar das limitações típicas dos estudos de casos, que impossibilitam a generalização dos resultados obtidos, deve-se destacar que, devido ao rigor metodológico aplicado, a abordagem de caráter exploratório, utilizando dados quantitativos e qualitativos, combinada aos estudos de casos selecionados de três organizações, sustentados na base teórica estudada e nos resultados apresentados, possibilitou a obtenção de conclusões importantes por meio desta pesquisa.

\section{Referências}

ADAMS, R.; BESSANT, J.; PHELPS, R. Innovation management measurement: a review. International Journal of Management Review, v. 8, n. 1, p. 21-47, 2006. http://dx.doi.org/10.1111/j.1468-2370.2006.00119.x

ANSOFF, H. I.; DECLERK, R. P.; HAYES, R. L. (Org.). Do Planejamento Estratégico à Administração Estratégica. São Paulo: Atlas, 1990.

CASTRO, H. G.; CARVALHO, M. M. Gerenciamento do portfolio de projetos: um estudo exploratório. Gestão \& Produção, v. 17, n. 2, p. 283-296, 2010. http://dx.doi. org/10.1590/S0104-530X2010000200006

CORMICAN, K.; O'SUlLIVAN, D. Auditing best practice for effective product innovation management. Technovation, v. 24, p. 819-829, 2004. http://dx.doi. org/10.1016/S0166-4972(03)00013-0

DAVILA, T.; EPSTEIN, M. J.; SHELTON, R. As Regras da Inovação. Porto Alegre: Bookman, 2007.

DODGSON, M.; GANN, D.; SALTER, A. The Management of Technological Innovation - Strategy and Practice. 2nd ed. Oxford University Press, 2008.

GARCIA, R.; CALANTONE, R. A critical look at technological innovation typology and innovativeness terminology: a literature review. Journal of Product Innovation Management, v. 19, p. 110-132, 2002. http://dx.doi.org/10.1016/S0737-6782(01)00132-1
GRAHAM, R. J.; ENGLUND, R. L. Creating an Environment for Successful Projects. 2nd ed. Jossey-Bass, 2004.

GRIFFIN, A. PDMA research on new product development practices: updating trends, and benchmarking best practices. Journal of Product Innovation Management, v. 14, p. 429-458, 1997. http://dx.doi.org/10.1016/ S0737-6782(97)00061-1

KENDALL, G. I.; ROLLINS, S. C. Advanced Project Portfolio Management and PMO: Multiplying ROI at Warp Speed. J. Ross Publishing, Inc., 2003.

KERZNER, H. Gestão de Projetos: as melhores práticas. Tradução de Marco Antônio Viana Borges, Marcelo Klippel e Gustavo Severo Borba. Porto Alegre: Bookman, 2002.

KILLEN, C. P.; HUNT, R. A.; KLEINSCHMIDT, E. J. Project portfolio management for product innovation. International Journal of Quality \& Reliability Management, v. 25, n. 1, 2008. http://dx.doi. org/10.1108/02656710810843559

KLEINSCHMIDT, E. J.; COOPER, R. G. The impact of product innovativeness on performance. Journal of Product Innovation Management, v. 8, p. 240-251, 1991. http://dx.doi.org/10.1016/0737-6782(91)90046-2

KUMAR, R.; AJJAN, H.; NIU, Y. Information Technology Portfolio Management: literature review, framework, and research issues. Information Resource Management Journal, v. 21, n. 3, p. 64-87, July/Sept 2008. http:// dx.doi.org/10.4018/irmj.2008070104

MAIDIQUE, M. A.; ZIRGER, B. J. A study of success, and failure in product innovation: the case of the US electronics industry. IEEE Transactions on Engineering Management, v. 1, n. 4, p. 192-203, 1984.

MARKOWITZ, H. Portfolio Selection. The Journal of Finance, v. 7, n. 1, p. 77-91, 1952.

McFARLAN, F. W. Portfolio approach to information systems. Harvard Business Review, v. 59, n. 5, p. 142-150, 1981.

NAGJI, B.; TUFF, G. Managing Your Innovation Portfolio. Harvard Business Review, May 2012.

ORGANIZAÇÃO PARA COOPERAÇÃO E DESENVOLVIMENTO ECONÔMICO - OCDE. Manual de OSLO: Diretrizes para coleta e interpretação de dados sobre inovação. 3. ed. FINEP, 2005.

PROJECT MANAGEMENT INSTITUTE - PMI. Um Guia do Conjunto de Conhecimento em Gerenciamento de Projetos (Guia PMBOK). 4. ed. Newton Square: Project Management Institute, 2008a.

PROJECT MANAGEMENT INSTITUTE - PMI The Standard for Portfolio Management - Second Edition. Project Management Institute Inc. Newtown Square: Project Management Institute, 2008b.

PORTER, M. E; STERN, S. Innovation: Location Matters. MIT Sloan Management Review, v. 42, n. 4, 2001.

SCHERER, F. O.; BIGNETTI, L. P.; CARLOMAGNO, M. S. Os Tipos de Inovação. Innoscience Consultoria em Gestão da Inovação. 2009. Disponível em: <http:// www.innoscience.com.br>. Acesso em: 13 jun. 2009. 
SOUSA, J. C. Processo de Inovação em Abordagem Multidisciplinar. Revista Eletrônica de Gestão Organizacional, v. 4, n. 2, maio/ago. 2006.

TERRA, J. C. C.; RIJNBACH, C. V.; BARROSO, A. Gestão de Portfólio - o desafio do alinhamento estratégico. TerraForum Consultores, 2009. Disponível em: <http:// www.terraforum.com.br>. Acesso em: 05 maio 2009.

TIDD, J.; BESSANT, J.; PAVITT, K. Gestão da Inovação. 3. ed. Porto Alegre: Bookman, 2008.
UTTERBACK, J. M.; ABERNATHY, W. J. A dynamic model of process, and product innovation. Omega, The International Journal of Management Science, v. 3, n. 6, p. 639-656, 1975.

YIN, R. K. Estudos de Caso: planejamento e métodos. 3. ed. Porto Alegre: Bookman, 2005.

ZAWISLAK, P. A. Contribuições para uma Medida Geral de Inovação. In: ENCONTRO DA ANPAD, 32., 2008, Rio de Janeiro. Anais... Rio de Janeiro, 2008. 